\title{
PRODUTIVIDADE DE UM SOLO LITÓLICO ASSOCIADA AO CONTROLE DA EROSÃO POR CORDÕES DE PEDRA EM CONTORNO(1)
}

\author{
F.J . da SILVA ${ }^{(2)}$ \& J .R.C. SILVA ${ }^{(3)}$
}

\begin{abstract}
RESUMO
Pesquisas prévias demonstraram a eficiência de cordões de pedra em contorno na redução do comprimento de encostas, no decrésci mo das taxas de enxurradas e de erosão, na retenção de sedimentos e de nutrientes e no decréscimo do assoreamento de reservatórios. 0 dimensionamento desse benefício em termos de produtividade do solo em regiões semi-áridas, entretanto, não fora ainda estabelecido. Este trabal ho foi desenvolvido no sentido de determinar os efeitos de cordões de pedra em contorno na produtividade de um solo litólico, determinada nas áreas de remoção do solo e nos locais onde os sedimentos eram retidos e depositados, treze anos após sua construção. 0 experimento foi executado em Quixadá (CE ), de março a jul ho de 1994. A produtividade natural do solo, não alterada por fertilizantes, foi avaliada em termos de rendimentos de feijão-de-corda e de milho e sua produção de biomassa. Em áreas de deposição, onde os sedimentos foram retidos pelos cordões de pedra em contorno, os aumentos no número de vagens por planta, no número e no peso de grãos por planta, e no rendimento de feijão-decorda, foram, respectivamente, de 48,6, 140,0, 86,4 e 85,5\%, quando comparados a esses parâmetros determi nados nas áreas de remoção do solo. A produção de mi lho também foi afetada beneficativamente pelos cordões de pedra em contorno, posto que a altura das plantas, o comprimento das espigas e o rendimento foram, respectivamente, $\mathbf{1 2 , 3}$ e 20,7\% maiores nos locais de deposição em relação às áreas de remoção do solo.
\end{abstract}

Termos de indexação: erosão, conservação do solo, cordões de pedra em contorno, produtividade.

\section{SUMMARY: PRODUCTIVITY OF A LITHOSOL IN ASSOCIATION WITH CONTROL OF EROSION USING STONE BARRIER CONTOURS}

Previous studies showed the effectiveness of stonebarrier contours on reducing sl opelengths, retaining sedi ment and nutrients, and decreasing runoff, erosion rateand sil tati on of reservoirs.

\footnotetext{
(1) Parte da Dissertação de Mestrado apresentada ao Departamento de Ciência do Solo da U niversidade Federal do Ceará, pelo primeiro autor. Financiada pelo CNPq e apresentada no XXV Congresso Brasileiro de Ciência do Solo, em Viçosa (MG), em 23-29 de julho de 1995. Recebido para publicação em junho de 1996 e aprovado em abril de 1997.

(2) Engenheiro-Agrônomo, Mestre em Solos e Nutrição de Plantas. Pró-Reitoria de Extensão - UFC. Caixa Postal 12.168. CEP 60355760 Fortaleza (CE).

(3) Professor Titular do Departamento de Ciência do Solo da Universidade Federal do Ceará. Bolsista do CNPq. Caixa Postal 12.168, CEP 60355-760 Fortaleza (CE).
} 


\begin{abstract}
Theextent of thesebenefits regarding to soil productivity in semiarid regions, however remained unknown. The aim of this study was to determine the effects of stone barrier contours on the productivity of a lithosol thirteen years after its construction. Experiments were carried out in areas of retained sedi ment and in areas wherethetopsoil layer was removed, in Quixadá, State of Ceará, Brazil, from March to J uly, 1994. Soil natural productivity was evaluated in both areas through yield and biomass production of cowpea (Vigna unguiculata) and corn (Zea mays). In areas of retained sediment, pod number per plant, grain weight per plant and yield of cowpea wererespectively $48.6 \%, 140.0,86.5$ and $85.5 \%$ higher than thoseparameters estimated in areas of removed soil. Corn production was also affected beneficially by stonebarrier contours since plant height, cob length and yield were 12.3, 20.7\% and 16.5\% higher in deposition sites than those in areas of removed soil.
\end{abstract}

Index terms: erosion, soil conservation, stonebarrier contour, soil productivity.

\section{INTRODUÇÃO}

Na região semi-árida do Nordeste brasileiro, a ausência de práticas conservacionistas e a alta intensidade das chuvas que se concentram na fase de preparo dos sol os, especialmente os rasos e com baixos teores de matéria orgânica, como os litólicos, intensificam, sobremaneira, os processos erosivos. As el evadas taxas de erosão que ocorrem têm provocado, ao longo dos anos, redução da área agricultável, baixo rendimento das culturas, assoreamento de rios e reservatórios, enchentes e danos às estradas, prejudicando o transporte dos insumos e a produção agrícola. Em conseqüência, agravam-se os prejuízos à produtividade do solo, à integridade do meioambiente e à rentabilidade do produtor.

Coberturas pedológicas nas quais predominam os sol os litól i cos são bastante representativas no Ceará, em termos deárea, ocupando cerca de 27.000 km², ou seja, $18,75 \%$ da superfície do Estado, e ocorrendo em todas as suas zonas fisiográficas (Ministério da Agricultura, 1973). Não obstante sua pequena profundidade efetiva, são intensivamente utilizados com culturas de subsistência, por agricultores de baixa renda, em sistemas de manejo com baixo nível tecnológico.

Com base na constatação da suscetibilidade dos solos litólicos à erosão, Silva \& Paiva (1985) recomendaram sua conservação por meio do emprego de cordões de pedra em contorno, ao demonstrarem sua eficiência na redução do assoreamento de reservatórios de água e os benefícios que os sedimentos retidos proporcionavam na melhoria das propriedades físicas, químicas e biológicas desses solos. Com princípio semelhante ao dos tradicionais cordões em contorno, essa prática funciona como uma barreira antierosiva, segmenta o comprimento dos declives e força a deposição de sedimentos nas áreas onde é construída, formando patamares naturalmente, impede o desgaste do solo provocado pela exportação de sedimentos, nutrientes e matéria orgânica e aumenta sua profundidade efetiva e a infiltração. Diminuindo o volume e a velocidade das enxurradas, os cordões de pedra também aumentam o armazenamento de água para as plantas (Rosso, 1982; Shaxson et al., 1989). Embora esses benefícios já tenham sido comprovados em outra pesquisa (Silva \& Silva, 1997), uma análise da produtividade do solo, avaliada pelo rendimento de culturas, ainda não fora desenvolvida para regiões semi-áridas.

Assim, o presente trabalho tem por objetivo determinar a eficiência dos cordões de pedra em contorno no aumento da produtividade de um solo litólico avaliada pela produção de biomassa e pelo rendimento de culturas de feijão-de-corda e milho, tanto em áreas sob proteção dessa prática conservacionista, quanto naquelas onde, por ausência de controle da erosão, predominam processos de remoção e transporte de sedimentos.

\section{MATERIAL E MÉTODOS}

O experimento foi realizado na Fazenda Lavoura Seca, pertencente à Universidade Federal do Ceará, no município de Quixadá (CE ), de 18 de março a 5 de julho de 1994. A área em estudo situa-se numa encosta ao norte de uma barragem vertedoura, cuja água supre parte da demanda da fazenda. Essa área estava, há 13 anos, sob pastagem natural, com sinais de superpastejo por bovinos e ovinos em al guns locais. $\mathrm{O}$ clima é do tipo BSw'h de Köppen, com normal pluviométrica de $705 \mathrm{~mm}$, dos quais $304 \mathrm{~mm}$ concentram-se na fase de preparo do solo e desenvolvimento inicial das culturas durantefevereiro e março. A isoterma anual é de $27^{\circ} \mathrm{C}$ e o período de estiagem ocorre no segundo semestre (Ministério da Agricultura, 1973).

O solo da área experimental é litólico eutrófico $A$ fraco textura média fase pedregosa caatinga hipoxerófila relevo suave ondulado substrato gnaisse, onde estão dispostos nove cordões de pedra em contorno, totalizando $2.180 \mathrm{~m}$ de comprimento, projetados e descritos por Silva \& Paiva (1985), coma finalidade de diminuir a intensidade de deposi ção de sedimentos na barragem vertedoura a jusante. Pedras com diâmetro médio de 0,15 m foram empilhadas a uma altura e largura aproximada de 0,40 m em todo o comprimento de cada cordão, previamente marcado em cima de curvas de nível, cujo espaçamento vertical variou de 0,50 a 3,50 m. O primeiro cordão de pedra dista 15 m da linha d'água do reservatório; o último, no divisor de água da vertente, dista $200 \mathrm{~m}$ dessa linha. Entreambos os cordões, estão os sete restantes, a espaçamentos variáveis de 17 a 24 m, em função da 
declividade. No topo da encosta, a uma declividade de $3 \%$, delimitou-se uma área de $25 \times 25 \mathrm{~m}$, na qual se procedeu à instalação das parcelas em delineamento experimental de blocos ao acaso, com quatro repetições dos seguintes tratamentos:

RF - Remoção em área cultivada com feijão-decorda;

RM - Remoção em área cultivada com milho; corda;

DF - Deposição em área cultivada com feijão-de-

DM - Deposição em área cultivada com milho.

Cada uma das dezesseis parcelas apresentava dimensões de $4 \times 2$ m com o comprimento no sentido do declive (Figura 1 ).

As parcelas correspondentes aos tratamentos DF e DM situavam-se imediatamente acima do cordão de pedra, onde se evidenciava a deposição de sedimentos retidos por essa prática, em camadas de $30 \mathrm{~cm}$ de espessura. Os sedimentos eram transportados das áreas onde era visível o efeito da erosão, correspondendo às parcelas RF e RM, situadas, por sua vez, a 19 macima do cordão de pedra. Para cada cultura, plantaram-se três linhas de $4 \mathrm{~m}$ de comprimento, em cada parcela, com espaçamento de $1 \times 0,20 \mathrm{~m}$, deixando-se cinco plantas por metro linear e60 plantas por parcela, correspondendo a uma população equivalente a 50.000 plantas ha-1. Os cultivares empregados nesses tratamentos foram: feijão-de-corda (Vigna unguiculata (L.) Walp.) cultivar E pace 11 e milho (Zea mays L.) variedade BR 5004 sel eção E pace $M-21$. Realizaram-se duas capinas com enxada, respectivamente, 18 e 29 dias após o plantio. Tendo em vista o estudo da produtividade natural do solo, as parcelas não receberam nenhuma adubação.

Colheu-se o feijão aos 83 dias e o milho aos 109 dias após o plantio. Para amostragem e comparação de médias dos tratamentos foram sorteadas quatro

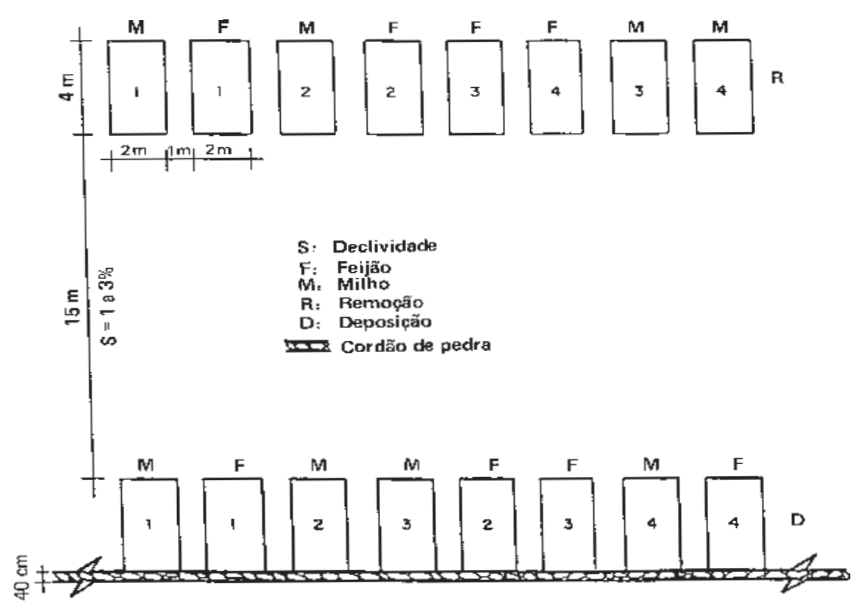

Figura 1. Esquema do experimento em campo, com a localização das parcelas na área de deposição dos sedimentos ( $D$ ) e na área de remoção do solo por erosão $(R)$, a primei ra situada imediatamente acima do cordão de pedra em contorno e, a segunda, a $19 \mathrm{~m}$ acima deste. plantas na linha central de cada parcela, excluindose as bordaduras, totalizando 16 plantas no tratamento RM e 16 plantas do tratamento DM. I dêntico procedimento foi efetuado para as plantas das parcelas nas quais se usou a cultura do feijão, totalizando 15 plantas notratamento RF e 15 no DF, em face da ocorrência da perda de duas plantas durante o processo de amostragem. Determinaramse os pesos dos grãos úmidos e secos e da parte aérea das plantas, utilizando-se uma bal ança digital, antes e após a secagem desses materiais em estufa $\left(a 60^{\circ} \mathrm{C}\right.$ ) durante 48 horas. No feijão, determinaram-se o número de vagens por planta e de grãos por vagem, o comprimento das vagens e o número total de grãos. No milho, foram determinados a altura das plantas, o número de espigas por planta, o comprimento de espigas e o número de grãos por espiga. Nessa cultura, avaliou-se também a diferença de cobertura do solo entre os tratamentos DM e RM, se os resíduos culturais do milho produzidos em cada tratamento fossem espalhados uniformemente em toda a área, utilizando-se, para tanto, a equação de Lopes et al. (1987):

$$
\mathrm{CS}=100\left(1-\mathrm{e}^{-0,000313 \mathrm{MR}}\right)
$$

onde: CS éa cobertura do sol o em percentagem e MR, a quantidade de restol hos de mil ho, determinada pela matéria seca das plantas expressa em kg ha-1.

$\mathrm{Em}$ todos os tratamentos, estabeleceu-se o rendimento das culturas a uma umidade dos grãos de $13 \%$.

Efetuou-se a análise da variância dos valores dos parâmetros biométricos e do rendimento das culturas nos tratamentos em estudo, aplicando-se o teste de Tukey a 5\%, para comparação das médias.

\section{RESULTADOS E DISCUSSÃO}

O quadro 1 mostra os resultados médios da altura das plantas, matéria seca, número de vagens e de grãos por planta, comprimento das vagens, número de grãos por vagem, peso seco dos grãos por planta e rendimento dos grãos para a cultura do feijão-de-corda nos tratamentos RF e DF.

O desenvolvimento do feijão foi beneficiado pela deposição de sedimentos, induzida pelo efeito conservacionista proporcionado pel o cordão de pedra em contorno, posto que todos os valores dos parâmetros estudados no tratamento DF foram, estatisticamente, superiores ao RF. Vale ressaltar os acréscimos de 75,9\% no número de vagens por planta, $103,2 \%$ no número de grãos por planta e $86,4 \%$ no peso de grãos por planta determinados notratamento DF, quando comparados ao RF. Provavel mente, a remoção de matéria orgânica, diminuição do teor de nutrientes, aumento do teor de Al e menor retenção de água afetaram a produtividade do sol o (Dedecek, 1987; Sparovek et al., 1993). Os acréscimos determinados nos parâmetros biométricos contribuíram, significativamente, para o incremento 
de $85,5 \%$ no rendimento do feijão-de-corda no tratamento DF $\left(411,9 \mathrm{~kg} \mathrm{ha}^{-1}\right)$, o qual superou em $189,8 \mathrm{~kg} \mathrm{ha}^{-1}$ o rendimento no $\mathbf{R} \mathbf{F}(222,1 \mathrm{~kg} \mathrm{ha}-1)$. Esseúltimo mostrou-seinclusiveinferior à baixíssima média de dez anos (1984-1993) dos rendimentos do feijão para o Ceará $\left(239,5 \mathrm{~kg} \mathrm{ha}^{-1}\right)$ enquanto o primeiro, mesmo com baixo rendimento, superou essa média decenal para o Nordeste brasileiro (322,3 kg ha-1), segundo dados do I BGE (1984 a 1993). Evidentemente, os baixos rendimentos foram conseqüência, principalmente, da ausência de fertilizantes e, particularmente, no tratamento RF , da pequena profundidade efetiva do solo, agravada pela alta taxa de erosão ao qual el e estava submetido.

Evidenciou-se, portanto, a eficiência do cordão de pedra em contorno na el evação da produtividade do solo, detectando-se o efeito prejudicial da erosão no rendimento da cultura no $\mathbf{R F}$, ao mesmo tempo em que se caracterizou o aumento da produção no DF , beneficiado pela ação antierosiva da prática em estudo.

Com referência à cultura do milho, no quadro 2 estão representados os val ores de al tura das plantas, matéria seca, número de espigas por planta, comprimento das espigas, número de grãos por espiga, peso seco dos grãos por planta e rendimento dos grãos nos tratamentos RM e DM.

O efeito do cordão de pedra em contorno no rendimento do milho foi evidenciado pelos maiores val ores de todos os parâmetros estudados, nas áreas de deposição (DM), de forma semelhante à que ocorreu na cultura do feijão. Entretanto, apenas os parâmetros altura das plantas e comprimento das espigas apresentaram diferenças significativas. E mbora não apresentando diferenças estatísticas significativas em relação ao tratamento $\mathbf{R} \mathbf{M}$, tanto os valores do número de grãos por planta quanto os do rendimento do milho foram, respectivamente, 27,7 e $16,5 \%$ mais altos nas parcelas onde houve deposição de sedimentos (DM) por influência da prática conservacionista. Em termos práticos, o acréscimo equivalente a $194,2 \mathrm{~kg} \mathrm{ha}-1$, proporcionado pelas melhores condições físicas e químicas do solo encontradas no tratamento $\mathbf{D M}$, representa mais de três sacas degrãos em cada hectare onde os sedi mentos são retidos pelos cordões de pedra em contorno. Além disso, orendimento de $1.368 \mathrm{~kg}$ ha-1 nesse tratamento, relativamente alto, considerando a ausência de fertilizantes, supera 2,5 a 3,5 vezes as baixas médias de dez anos indicadas pelo IBGE (1984 a 1993) para Quixadá (393,8 kg ha-1), Estado do Ceará (448,1 kg ha-1) e região Nordeste $(534,7$ kg ha-1).

Esses resultados atestam a eficiência dos cordões de pedra em contorno na deposição e retenção de sedimentos e água por comparação à situação onde a remoção empobrece gradativamente o solo (Silva et al., 1985; Dedecek, 1987; Sparovek et al., 1991; Mokma \& Sietz, 1992; Weesies et al., 1994). A figura 2 ilustra um esquema da deposição do solo transportado e retido pelo cordão de pedra em contorno, observando-se a diferenciação do porte e da biomassa das plantas em função de sua proximidade do cordão de pedra. $\grave{A}$ medida que as plantas se afastam da barreira antierosiva, suas alturas, produção de biomassa e cobertura vegetativa do solo diminuem.

Quadro 1. Valores médios dos parâmetros biométricos e de rendi mento da cultura nos tratamentos remoção em área cultivada com feijão-de-corda (RF) e deposição em área cultivada com feijão-de-corda (DF)

\begin{tabular}{|c|c|c|c|c|c|c|c|c|}
\hline \multirow{2}{*}{ Tratamento } & \multicolumn{4}{|c|}{ Planta } & \multicolumn{2}{|l|}{ Vagem } & \multicolumn{2}{|l|}{ Grão } \\
\hline & Altura & Matéria seca & Vagens & Grãos & Comprimento & Grãos & Peso seco/planta & Rendimento \\
\hline & $\mathrm{cm}$ & $g$ & no & - & $\mathrm{cm}$ & no & $g$ & $\mathrm{~kg} \mathrm{ha}^{-1}$ \\
\hline RF & $42 a$ & $3 a$ & $2,9 a$ & $30,9 a$ & $17,5 a$ & $10,4 a$ & $4,4 a$ & $222,1 a$ \\
\hline DF & $62,4 b$ & $7,2 b$ & $5,1 b$ & $62,8 b$ & $18,5 b$ & $12,5 b$ & $8,2 b$ & $411,9 b$ \\
\hline DMS & 13,6 & 1,5 & 1,3 & 2,4 & 1 & 1,3 & 2,4 & 121,5 \\
\hline
\end{tabular}

Os valores seguidos de letras iguais nas colunas não diferem entre si pelo teste de Tukey ao nível de $5 \%$.

DMS: Diferença mínima significativa $(0,05)$.

Quadro 2. Valores médios dos parâmetros biométricos e de rendi mento da cultura nos tratamentos remoção em área cultivada com milho (RM) e deposição em área cultivada com milho (DM)

\begin{tabular}{|c|c|c|c|c|c|c|c|}
\hline \multirow{2}{*}{ Tratamento } & \multicolumn{3}{|c|}{ Planta } & \multicolumn{2}{|c|}{ Espiga } & \multicolumn{2}{|c|}{ Grão } \\
\hline & Altura & Matéria seca & Espigas & Comprimento & Grãos & Peso seco/planta & Rendimento \\
\hline & $\mathrm{cm}$ & $\bar{g}$ & no & $\mathrm{cm}$ & $\mathrm{n} \cap$ & $g$ & $\mathrm{~kg} \mathrm{ha}^{-1}$ \\
\hline RM & $141,2 \mathrm{a}$ & $30,7 a$ & $0,9 a$ & $8,7 a$ & $102,8 a$ & $23,5 a$ & $1.173,8 \mathrm{a}$ \\
\hline DM & $158,6 b$ & $36,3 a$ & $1 a$ & $10,5 b$ & $131,3 a$ & $27,4 a$ & $1.368,0 \mathrm{a}$ \\
\hline DMS & 12,9 & 10,7 & 0,8 & 1,7 & 46,9 & 7,9 & 393,5 \\
\hline
\end{tabular}

Os valores seguidos de letras iguais nas colunas não diferem entre si pelo teste de Tukey ao nível de 5\%.

DMS: Diferença mínima significativa $(0,05)$. 


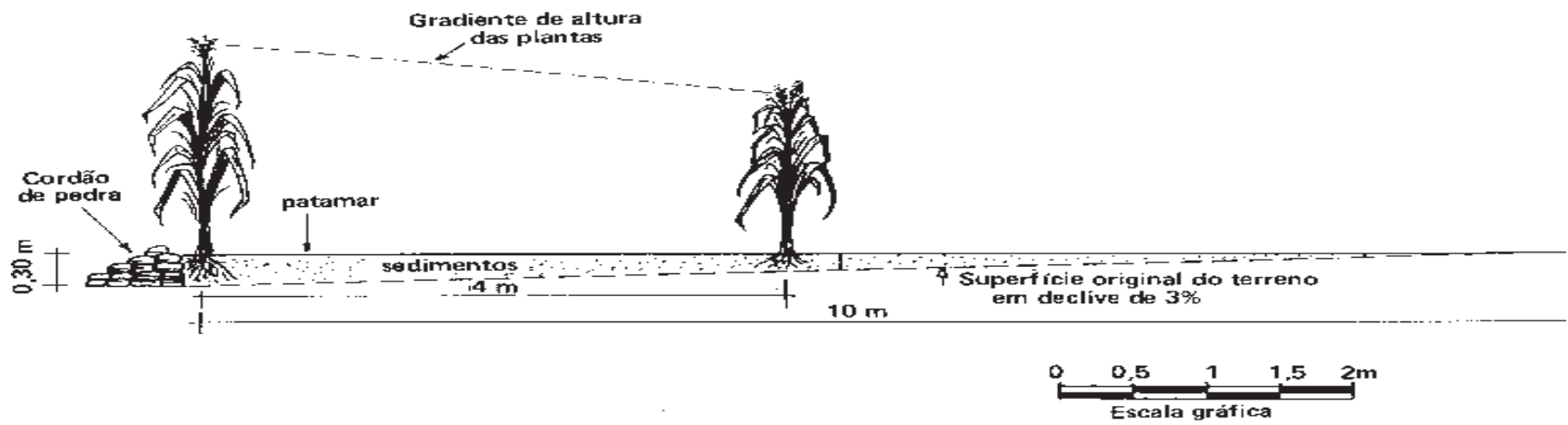

Figura 2. Esquema representativo da acumulação de sedimentos pelo cordão de pedra em contorno, observando-se a diferença de altura da primeira e da última plantas nas parcelas do tratamento $D$ (secção transversal).

Considerando-se o declínio usual dos níveis de matéria orgânica nos solos cultivados, não é desprezível o acréscimo de $18,2 \%$ de matéria seca da parte aérea, proporcionado pelas plantas do tratamento DM (1.815 kg ha-1), em relação àquelas do RM (1.535 kg ha-1), tomando-se por base uma população de 50.000 plantas ha-1. E mbora não determinado, élícito esperar um aumento proporcional de bi omassa também nosistema radicular das plantas. Aplicados esses val ores de massa dos restol hos, como cobertura morta, à equação de L opes et al. (1987), são obtidos valores de cobertura do solo iguais a 43,3 e 38,2\% para os tratamentos $\mathbf{D M}$ e $\mathbf{R} \mathbf{M}$ respectivamente. Esse acréscimo anual de biomassa e de cobertura do solo, induzido pelos cordões de pedra em contorno, revela-se útil à dissipação da energia cinética das gotas de chuva, na maior proteção dos agregados, na diminuição das taxas de erosão, na conservação da umidade do solo e na reciclagem de nutrientes dos tecidos vegetais (Lombardi N eto et al., 1988; Bragagnolo \& Mielniczuk, 1990; Carval ho et al ., 1990; Alves et al., 1995). Além disso, o maior suprimento dessa biomassa da parte aérea e das raízes, repetido anualmente, elevará o patamar do teor de matéria orgânica nas ár eas protegi das pel os cordões de pedra, com todas as vantagens que ela proporciona ao solo, inclusivena mel horia de sua condição microbiológica, que constitui um fator da maior importância para sustentação da produtividade, porém desprezado na agricultura de bai xo nível tecnológico de regiões semiáridas do país. Ao contrário, no tratamento R M reproduziu-se o círculo vicioso da menor cobertura do solo, maior erosão, menor produtividade e menor proteção, processo esse que se agrava ano a ano. Esse é o cenário típico de vastas áreas semi-áridas do Nordeste, onde, em face da ausência de práticas conservacionistas, predominam processos de remoção do solo, os quais, agravados pel o superpastejo, podem conduzir os sol os ao limiar da desertificação (Dregne, 1978).

\section{CONCLUSÃO}

Os cordões de pedra em contorno constituem eficiente prática que concorre para o aumento da produtividade do solo, induzindo incrementos nos valores de todos os parâmetros biométricos e de rendimento das culturas de milho e feijão-de corda, em áreas onde sua ação antier osiva produz a retenção e deposição de sedimentos. Nas áreas situadas fora do raio de ação dessa prática conservacionista, assumem importância processos de remoção e transporte de massas (solo) com menor produção de bi omassa e conseqüente redução da cobertura do sol o e da produção de matéria orgânica, reproduzindo uma síndrome comum a algumas regiões do Nordeste brasileiro que pode culminar em processos de desertificação.

\section{LITERATURA CITADA}

ALVES, A.G.C.; COGO, N.P. \& LEVIEN, R. Relações da erosão do solo com a persistência da cobertura vegetal morta. R. bras. Ci. Solo, Campinas, 19:127-132, 1995.

BRAGAGNOLO, N. \& MIELNICZUK, J. Cobertura do solo por resíduos de oito seqüências de culturas e seu relacionamento com a temperatura e umidade do solo, germinação e crescimento inicial do milho. R. bras. Ci. Solo, Campinas, 14:91-98, 1990

MINISTÉ RIO DA AGRICULTURA. Levantamento exploratório e de reconhecimento de solos do Estado do Ceará. Recife, Divisão de Pesquisa Pedológica, 1973. 310p. v.1, (Série Pedológica)

CARVALHO, F.L.C.; COGO, N.P. \& LEVIEN, R. Eficácia relativa de doses e formas de manejo do resíduo cultural de trigo na redução da erosão hídrica do sol o. R. bras. Ci. Solo, Campinas, 14:227-234, 1990.

DEDECEK, R.A. Efeitos das perdas e deposição de camadas de solo na produtividade de um latossolo vermelho-escuro dos cerrados. R. bras. Ci. Solo, Campinas, 11:323-328, 1987.

DREGNE, H.E. Desertification: man's abuse of the land. J. Soil Wat. Cons., Ankeny, 33:11-14, 1978.

INSTITUTO BRASILEIRO DE GEOGRAFIA E ESTATÍSTICA. Produção agrícola municipal. Rio de J aneiro, 1984, 1985, 1986, 1987, 1988, 1989, 1990, 1991, 1992 e 1993. (Número de páginas variável em função do ano) 
LOMBARDI NETO, F.; DE MARIA, I.C.; CASTRO, O.M. de; DECHEN, S.C.F. \& VIEIRA, S.R. Efeito da quantidade de resíduos culturais de milho nas perdas de solo e água. $R$. bras. Ci. Solo, Campinas, 12:71-75, 1988.

LOPES, P.R.C.; COGO. N.P. \& LEVIEN, R. Eficácia relativa de tipos e quantidades de resíduos culturais espalhados uniformemente sobre o sol o na redução da erosão hídrica. R. bras. Ci. Solo, Campinas, 11:71-75, 1987.

MOKMA, D.L. \& SIETZ, M.A. Effects of soil erosion on corn yields on Marlette soils in south-central Michigan. J. Soil Wat. Conserv., Ankeny, 47:325-327, 1992.

Rosso, A. A conservação do solo através de patamar. In: CONGRESSO BRASILEIRO DE CONSERVAÇÃO DO SOLO, 4., Campinas, 1982. Resumos. Campinas, Sociedade Brasileira de Ciência do Solo, 1982. p.10.

SHAXSON, T.F.; HUDSON, N.W.; SANDERS, D.W.; ROOSE, E. \& MOLDENHAUER, W.C. Land husbandry: a framework for soil and water conservation. Soil and Water Conservation Society/World Association of Soil and Water Conservation, Ankeny, 1989. 64p.
SILVA, J.R.C.; COELHO, M.A.; MOREIRA, E.G.S. \& OLIVEIRA NETO, P.R. Efeitos da erosão na produtividade de dois solos da classe Latossolo Vermelho-Amarelo. R. Ci. Agron., Fortaleza, 16:55-63, 1985.

SILVA, J.R.C. \& PAIVA, J.B. Retenção de sedimentos por cordões de pedra em contorno em uma encosta de solo litólico. R. bras. Ci. Solo, Campinas, 9:77-80, 1985.

SILVA, J.R.C. \& SILVA, F.J . da. Eficiência de cordões de pedra em contorno na retenção de sedimentos e melhoramento de propriedades de um solo litólico. R. bras. Ci. Solo, Viçosa, 21:441-446. 1997.

SPAROVEK, G.; J ONG VAN LIER, Q.; ALOISI, R.R. \& VIDALTORRADO, P. Previsão do rendimento de uma cultura em solos de Piracicaba em função da erosão. R. bras. Ci. Solo, Campinas, 17:465-470, 1993.

SPAROVEK, G.; TERAMOTO, E.R.; TORETA, D.M.; ROCHELE, T.C.P. \& SHAYER, E.P.M. Erosão simulada e a produtividade da cultura do milho. R. bras. Ci. Solo, Campinas, 15:363-368, 1991. 